Investigaciones sobre sociabilidad, asociacionismo y prácticas políticas. Introducción.

Nicolás QUIROGA

Avances del Cesor, V. XIII, No 14, Primer semestre 2016, pp. 113-115.

ISSN 1514-3899 / ISSNe 2422-6580 - http://web2.rosario-conicet.gov.ar/ojs/index.php/AvancesCesor/index

\title{
Investigaciones sobre sociabilidad, asociacionismo y prácticas políticas. Introducción.
}

\section{Research on Sociability, Associationism and political practices Introduction}

\author{
Nicolás Quiroga \\ Consejo Nacional de Investigaciones Científicas y Técnicas \\ Centro de Estudios Históricos \\ Universidad Nacional de Mar del Plata \\ (Argentina) \\ nfquirog@gmail.com
}

Algunos de los artículos que integran este dossier fueron antes ponencias en la mesa "Asociacionismo" de las IV Jornadas Interdisciplinarias de Investigaciones Regionales "Enfoques para la historia", realizadas en el CCT Conicet de Mendoza, entre el 7 y el 9 de octubre de 2015.

Tanto en aquella mesa (que coordiné junto con Patricia Barrio) como en este dossier, un término para las series de textos que los integran es diversidad. Cuando no está troquelada por grupos dados por supuesto, la idea de sociabilidad se mixtura con otros conceptos y otras maneras de reflexionar el tándem cultura e identidad. No solo las temáticas son variadas sino también las expectativas que las investigaciones depositan en las maniobras a las que someten al término "sociabilidad" o al de "asociaciones”. Leyendo la carpeta, más allá de cada uno de los textos, podemos conjeturar un efecto no tan previsible: allí donde más se espera que la sociabilidad explique la elección 
política, la densidad de los agrupamientos o las demandas de las asociaciones, es donde las supuestas consecuencias tienen más repercusiones sobre la sociabilidad. Lo que puede ser estrabismo en el dominio de las clasificaciones y la ponderación, también puede obedecer a un sobredimensionamiento del lugar de los efectos en los estudios sobre las prácticas. Esa crítica ha servido de fundamento a muchas investigaciones que no dieron por cerrada la relación entre asociación $y$ sociabilidad $y$ hallaron heterogeneidad de la segunda en los márgenes difusos de la primera. También se ha pensado la variedad en la relación entre prácticas y creencias. ¿Qué sucedería en cada uno de estos artículos si lo que suponemos común a las personas no fuera algo previo a la acción sino parte misma de esas actividades? ¿Qué sucedería si imaginamos la sociabilidad como un disfraz y no como aquello investido por otra cosa? Disfraz es una manera de decir representación. ${ }^{1}$ ¿Por qué deberíamos suponer que la diversidad en el orden de las representaciones provoca debilidad en el orden de las sociabilidades?

Una vez aceptada la idea de heterogeneidad, sin embargo, las encrucijadas continúan surgiendo. Es que, en algunos casos, la variación se celebra, se conjeturan articulaciones entre los elementos del conjunto, propiedades del montón; y en otros se la aplaca con definiciones de la ratio de la conflictividad y las asimetrías. ¿La sociabilidad podría ser un factor contencioso más que ese geist

1. BISSO, Andrés “¿El de gaucho o el de Tom Mix? Reflexiones políticas a partir de los horizontes de identidades prestadas en disfraces y personificaciones lúdicas en la provincia de Buenos Aires durante los carnavales de la época fresquista, 1936-1940”, en BISSO, Andrés, KAHAN, Emmanuel y SESSA, Leandro, Formas politicas de celebrar y conmemorar el pasado (19301943), Ceraunia, La Plata, 2014. entrevisto? ¿O deberíamos decir "imaginado"? Tampoco resulta sencillo distinguir cuándo esa diversidad está en el registro "nativo" y cuándo surge de las clasificaciones acuñadas en el escritorio de la historia. Es este último lugar un verdadero desafío para pensar un término elástico y esquivo, y no debido a que la interpretación de los historiadores sea menos necesaria o "secundaria" respecto de las experiencias del pasado, sino porque no está claro si todas esas nociones que circulan alrededor de "sociabilidad" surgen de la maduración de un espacio temático o si son los añicos de un "campo" que aún no define nuevas agendas.

Este breve dossier también presenta una variedad de trazos alrededor de esa tensión entre "leer" asociaciones y "leer" sociabilidades. Las relaciones entre asociaciones y política se desplazan hasta el eje de las sociabilidades en el artículo de Marcelo Jeréz ("Asociacionismo vecinal en Jujuy en el tránsito hacia al primer gobierno peronista. Prácticas, continuidades y tensiones"), en tanto las coordenadas barriales $\mathrm{y}$ de clase se sugieren como modalidades específicas para el trabajo del fomentismo durante el peronismo. La madeja que anuda prácticas asociativas en barriadas humildes con el voto peronista se hace más densa si la geografía es Jujuy y la experiencia del "tanquismo" redimensiona el lazo político presupuesto.

En el artículo de Bruno Cimatti, "Fascistas y antifascistas en las elecciones de la Sociedad Italia Unita de Bahía Blanca (enero de 1927)", por otro lado, la sociabilidad etnicizada y la articulada bajo la fórmula del antifascismo son supuestas para reconstruir una elección en una asociación italiana en los años '20. E1 desplazamiento en ese caso se produce hacia 
la política local, y las modalidades políticas corroen cualquier viso de esencialismo para pensar el asociacionismo.

Emiliano Casas, en "Los lazos de los gauchos. La sociabilidad como herramienta para la difusión de la tradición en la provincia de Buenos Aires, 1930-1950", avanza desde la indagación sobre centros tradicionalistas hacia la reflexión sobre el criollismo. La reconstrucción de los circuitos artísticos nos propone interrogarnos sobre la sociabilidad investida de motivos gauchescos. Percibimos actualmente un interés creciente en las preguntas sobre las culturas populares antes del peronismo (Matthew Karush) o en cuestionarios que cortan a través de la serie política (Ezequiel Adamovsky), y el artículo de Casas dialoga con nuevos enfoques sobre la Argentina de mediados del Siglo XX.

Esa es también la intención de mi artículo ("Mezclando cosas. Migrantes internos, peronismo y temperamentos regionales"): reponer una abundante bibliografía que no descansa en el anaquel de las investigaciones sobre sociabilidad política pero que, creo, contribuye notoriamente a complejizar esa cantera. Para eso retomo una vieja y recurrente discusión en los estudios sobre peronismo como es la de los migrantes internos y el voto peronista.

Finalmente, conviene remarcar otra propiedad de la serie, además de su heterogeneidad. Los estudios sobre asociacionismo -en mayor medida que los enfocados en sociabilidades- tienen mucha y buena trayectoria en la historiografía argentina. Más allá de algunas referencias indispensables, como son los escritos de Pilar González Bernaldo, esta serie no parece anclar sus investigaciones en una conversación con problemáticas fuertes en aquellas líneas de investigación, incluso cuando los temas que retoma encontrarían en ese diálogo abundantes pistas. ¿Se debe esto a que las investigaciones sobre asociacionismo y sociabilidades son más bien una ruta secundaria en la investigación actual, a la que se llega para "enriquecer" el paisaje de sus avenidas principales? Pienso que los signos de interrogación son convenientes porque dejan abierta la posibilidad de inscribir los textos de este dossier en futuras agendas que no subrayen la variación, aunque la celebren, e instalen la necesidad de repensar y discutir enfoques, además de incentivar la reconstrucción de casos.

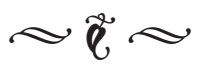

